\title{
Learning Style identification and usage in academia: A systematic mapping
}

\author{
Miguel Alvim de Almeida ${ }^{1}$, Jairo Francisco de Souza ${ }^{1}$, Eduardo Barrére ${ }^{1}$ \\ ${ }^{1}$ Graduate Program in Computer Science \\ Federal University of Juiz de Fora (UFJF) \\ 36.360-900 - Juiz de Fora - MG - Brazil \\ \{miguel.alvim, jairo.souza, eduardo.barrere\}@ice.ufjf.br
}

\begin{abstract}
The different learning style models and applications might be an obstacle for those who are seeking to start to work in this field. Also, one might not be able to find some key papers that many regards as good starting points. This paper presents a systematic mapping, done with 102 papers, in regards to learning style identification and usage, and seeks to create a starting point for those who are starting to work on these research fields. The results show the predominance of a few learning style models and learning object metadata models. Also, there is a high amount of works focusing on personal solutions with non-automatic detection and adaptation models.
\end{abstract}

Keywords: Learning Style, Learning Object, Learning Management System

\section{Introduction}

As technology advances in an ever faster pace and the world becomes more and more interconnected, thanks, mostly, to communication and computer technology, the possible ways that information can be disseminated, absolved and interpreted grows with it. Since this new paradigm has changed some of the ways that people interact, think, learn and behave [Turkle 2004], it is necessary to also change the way that we pass knowledge, specially in this new computerized environment, if we wish to better accommodate the though processes of the computer literate students of our era.

Several authors have proposed Learning Style (LS for short) Theories accompanied by a model. These Learning Style Models (LMS) are usually used as tools, or perhaps better phrased, concepts, to create a more suitable educational content/learning material (educational material, in any format, is denominated a Learning Object, or LO).

A Learning Style Theory refers to the idea that different people have different preferences on how to absorb knowledge/information, and these preferences can be identified and categorized in a way that one can make LO that better suit them [Coffield et al. 2004].

As suggested by the word "theories", there is not a single unified idea on how one's learning works. As a demonstration, the systematic review of [Coffield et al. 2004], done in the beginning of the decade of 2000, identified more than $\mathbf{5 0}$ different learning style models. This work itself found several theories in use as well.

These theories can be applied in any educational environment. A very popular way of usage is found on computerized environments, mostly through the use of virtual Learning Management Systems (LMS). These systems offer several tools that allow teachers and students to interact in a virtual environment, facilitating the process of knowledge passing 
by the teacher and activity and evaluation making by the student; the most complete ones usually allow such interaction to happen without any physical contact, and are currently the main tools used for distant learning through the internet, or as is more commonly known, eLearning, as defined by [Nichols 2003].

The existence of several different LS can make the task of choosing one with the right tools or the act of starting to do research on the field somewhat daunting, creating an unnecessary barrier of entry for some people. This mapping seeks to remedy this problem by pointing out the main tendencies of the research and usage (as well with the availability of those tools) done with LS and LO in a compact and digestible format (as we were unable to detect a current work with a similar goal in the english language). Its ultimate goal is to be able to set a forward direction for those seeking to start working with LS and LO usage in the academic and scientific fields.

\section{Related Works}

As this is a field that is under study for decades, other works attempting to map and review it have already been done. In [do Nascimento et al. 2017] a systematic review of the recommendation of LO based on LS is executed. In their work a total of 49 papers are analyzed and is concluded that FSLSM (Felder \& Silvermand Learning Style Model) is the most widely used LS, along with the Learning Object Metadata (LOM) as the metadata standard for the specification and categorization of LO. This review focus on how and where LS are being used, but does not attempt to give a starting point for new researchers on where to start their own research.

In [Coffield et al. 2004], a thoroughly systematic review of several Learning Styles Models and their classification questionnaires is done, getting into the merits of their validity, application and on which elements inherent of the person doing the questionnaire are used for their Learning Style classification. This work is cited in several other relevant works in the LS field and might be the most complete review on the subject to this date. However, this review does not touch on some of the most currently used Learning Style Models, like the Felder \& Silverman and VARK models, what does not help if ones seek to understand the current state of usage and validity of the field.

In [Egaña et al. 2018], 15 questionnaires used for LS identification have their usage and validity discussed and analyzed. This work focus on finding the usage of the main questionnaires previously studied by [Coffield et al. 2004] along with another few who were originally discarded by them, under the reason of being insufficient in one or more prerequisites. Their research was done with publications in Spanish and English, with finds that point towards the fact that the questionnaires, who were deemed the most reliable by [Coffield et al. 2004] were the least used in current studies, with the VAK/VARK and the Ferlder-Silverman models questionnaires being by far the most used. This paper discusses the validity of those questionnaires and of LS themselves, with no focus on the location where these questionnaires are applied nor indication of where to obtain them. In overall, this is an interesting research that helps those who already have some previous knowledge about the subject and to those who are new to it, but attempting to give a proper starting point for newcomers is not one of it's goals. 
VIII Congresso Brasileiro de Informática na Educação (CBIE 2019)

Anais do XXX Simpósio Brasileiro de Informática na Educação (SBIE 2019)

\section{Methodology}

This mapping follows the procedures proposed by [Petersen et al. 2008], where the search for the primary works is done through the use of a search string based on a set of primary questions (our objectives) that we seek to answer. The string is used on a set of scientific and academic works databases in order to obtain an initial set of works for the mapping. Then through a process of evaluation of the title, the abstract, the key words and the overall content, we trim the works obtained to a set with a more manageable amount, and relevant, works, who is then fully read and analyzed.

\subsection{Objectives}

This review sought to answer the following key questions:

1. What are the learning style models in use today?

2. How said learning styles are identified?

3. What are the available resources for such learning style models?

\subsection{Databases}

The following databases were used: Scopus, ACM Digital Library, IEEExplore and CEIE (Portal de Publicações da Comissão Especial de Informática na Educação - Portal of the Special Commission on Informatics in Education).

\subsection{Search Expression}

In order to formulate our search string, we made use of a string similar to the one used in [do Nascimento et al. 2017]. This String is formulated through the idea of Population, Intervention, Comparison and Outcome, as is used by [Petersen et al. 2008, Kitchenham and Charters 2007]. The population was set as "Learning Styles" and it's Portuguese equivalent term. Our outcomes were the "Learning Objects" and related therms, that are either generated, linked or recommended in relation to the application of said Learning Styles. We did not made use of intervention nor comparison, as we did not seek any specific solution to an issue related to Learning Styles (intervention) and as such, we had no need to compare (comparison) it to anything in particular. The final search string was defined as follows:

((“Learning Style” OR “Learning Styles” OR "Estilo de Aprendizagem” OR "EstiLO de Aprendizagem”) AND ("Learning objects" OR "learning object" OR “Objetos de aprendizagem” OR "Objeto de Aprendizagem"))

\subsection{Criteria of inclusion}

1. The paper is in English or in Portuguese.

2. The paper discuss or presents the use of a Learning Style Model.

\subsection{Criteria of exclusion}

1. The paper is not available.

2. No active use of a Learning Style Model (be it a specific one or a generic one such as in the cases of general LO recommending systems) in conjunction with Learning Objects.

3. The paper is a systematic review or similar kind of work.

4. Usage of Learning Objects without a Learning Style (be it a specific model or a general idea of the application of a model).

5. The manuscript is not a full paper. 
VIII Congresso Brasileiro de Informática na Educação (CBIE 2019)

Anais do XXX Simpósio Brasileiro de Informática na Educação (SBIE 2019)

\subsection{Data Extraction}

By using the search string, we obtained 291 works from Scopus, 105 from ACM (using the "ACM Guide to Computing Literature"), 85 from IEEExplore and 31 from CEIE. The searches were all done on the May of 2019, resulting in a total of 512 results.

In total, 13 papers out of the 512 total were excluded due to the first exclusion criterium, after that a further total of 110 were removed as duplicates. Out of the 389 left, a total of $102^{1}$ were selected after a complete abstract read and checking availability of the text. The remaining eliminated papers met the third exclusion criterium. These 102 articles were then fully read.

The Table 1 shows the 20 most significant terms found in common on all the 102 papers' abstracts. This table has been created in order to better demonstrate the most common ones used in the field.

\begin{tabular}{ccccc} 
Words (1st to 10th) & Total Amount & & Words (11th to 20th) & Total Amount \\
\cline { 2 - 5 } \cline { 4 - 5 } learning & 4788 & & personalized & 357 \\
style & 1820 & & course & 322 \\
system & 1246 & & educational & 287 \\
object & 1225 & & preferences & 238 \\
student & 1197 & & study & 217 \\
learner & 756 & & teaching & 217 \\
model & 637 & & knowledge & 203 \\
students & 623 & & adaptation & 175 \\
adaptive & 490 & environment & 168 \\
e-learning & 371 & materials & 168 \\
\hline
\end{tabular}

Tab. 1. Most common words on all the papers abstracts

\section{Review report}

After the read of the papers, it was verified that all of them worked in computerized environments, focusing on LMSs (such as Moodle, with 8 works) or singular computerized learning tools (mostly, of personal authoring of a member of the research). This fact can be attributed to a legitimate trend in the LS models application field to go towards electronic assisted learning and/or eLearning or to a bias of our research approach, by possibly focusing on repositories that mostly work with research in the STEM (Science, Technology, Engineering and Mathematics) fields.

We do not support the second possibility, since we used the Scopus database, which catalogues more than 30,000 scientific works on the fields of life sciences, social sciences, physical sciences and health sciences. It means that our search also contemplated works on those fields and, still, did not obtain many (if any) relevant papers, and the few ones that we obtained were excluded due to the exclusion criteria.

\subsection{Question 1: What are the learning style models in use today?}

This question focuses on creating a list of LS based on their usage in academic works. As we evaluate the data, it is important to note that the emphasis is on the word "academic",

\footnotetext{
${ }^{1}$ The full list of the 102 papers can be downloaded at http: / / bit. Iy/2019SBIEMapping
} 
VIII Congresso Brasileiro de Informática na Educação (CBIE 2019)

Anais do XXX Simpósio Brasileiro de Informática na Educação (SBIE 2019)

and therefore it is possible to attribute the lack of appearance of certain known LS to the fact that they are not very discussed in academia.

In order to gather the data to answer this question we considered a LS to be used if it or main characteristics of it were adopted as the main LS in the article. The results can be found in Figures 1 and 2. The full name and work of origin of each Learning Style Model can be found in Table 2.

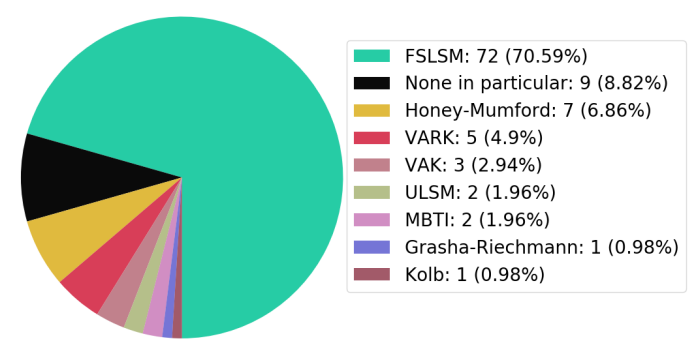

Fig. 1. Total Learning Style Usage in all Articles

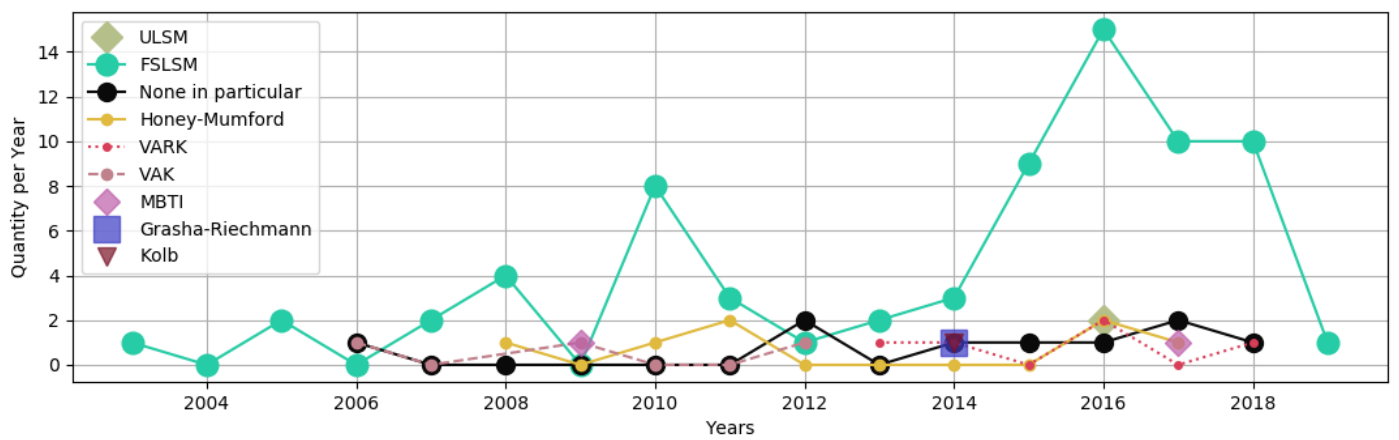

Fig. 2. Learning Style Usage through the Years

\begin{tabular}{|c|c|c|}
\hline LMS Name & Known by & Initial Release Citation \\
\hline $\begin{array}{l}\text { Felder \& Silverman } \\
\text { Learning Style Model }\end{array}$ & FSLSM & [Felder et al. 1988] \\
\hline Honey \& Mumford & - & [Honey and Mumford 1982a] \\
\hline Visual Auditory Kinesthetic & VAK & [Barbe et al. 1979] \\
\hline $\begin{array}{c}\text { Visual Auditory } \\
\text { Read/Write Kinesthetic }\end{array}$ & VARK & [Fleming and Mills 1992] \\
\hline Unified Learning Style Model & ULSM & [Popescu 2010] \\
\hline Myers Briggs Type Indicator & MBTI & [Briggs and Myers 1944] \\
\hline Grasha-Riechmann & - & [Riechmann and Grasha 1974] \\
\hline Kolb & - & [Kolb 1984] \\
\hline
\end{tabular}

Tab. 2. Full names and Source of the Learning Styles

There is a substantial predominance of the Felder \& Sivelman model over all other styles, with a total of $\mathbf{7 0 . 5 9 \%}$ of all evaluated works using the model in a direct manner, with the second LS model in usage being the one by Honey \& Muford with only $6.86 \%$, cLOely followed by the VARK LS model, with $\mathbf{4 . 9 0 \%}$. The element named "None in 
VIII Congresso Brasileiro de Informática na Educação (CBIE 2019)

Anais do XXX Simpósio Brasileiro de Informática na Educação (SBIE 2019)

particular" refers to articles that make a generic usage of the therm "Learning Style", by working on LO recommendation in a system that is LS agnostic (as in, it may admit many different LS types).

A interesting example is [Londoño et al. 2018], which uses 2 different LS models (VARK and FSLSM) in a hybrid model.

Another thing that is worth to point out is that the Myers Briggs Type Indicator (MBTI) is not a LS per see, however, its ability to help one's identifying dominating personality and preference traits can be used to create LO and to choose teaching methods.

\subsection{Question 2: How said learning styles are identified?}

Of the 102 articles, $\mathbf{5 3}$ did not use a method to detect the LS of the model that they used. These works generally focused on the recommendation of LO aspect of their systems and not getting into the merit of identifying their users' LS. Out of the 102, 55 made use of a questionnaire as a tool to assert a student learning style according to the model used.

Lastly it is also important to note that $\mathbf{6}$ made attempts to also detect a student learning styles by usage of automatic methods, usually after a initial evaluation through a questionnaire. The methods used to detect were: Ant Colony, Bayesean Networks, Classification through different Statistical analysis methods, Neural Networks, Semantic Linked Networks, Clusterization, Genetic Algorithms and Data Mining. In total, 12 different methods were used in the 6 articles.

\subsection{Question 3: What are the available resources for such learning style models?}

As mentioned on the section 4.2, the absolute majority of the read works that used LS identification made use (mostly only) of questionnaires to obtain a student LS. These questionnaires are actually standardized, with most LS models having at least one available, as demonstrated in Table 3.

\begin{tabular}{cccc}
$\begin{array}{c}\text { Questionnaire } \\
\text { Name }\end{array}$ & $\begin{array}{c}\text { LS Model } \\
\text { Name }\end{array}$ & Source & Available \\
\hline Index of Learning Styles (ILS) & FSLSM & [Felder and Soloman 1997] & YES \\
Enhanced Learning Style Index (ELSI) & FSLSM & [Hamada and Hassan 2017] & NO \\
Cuestionario Honey-Alonso de & Honey \& Mumford & [Alonso and Gallego 2000] & YES \\
EstiLO de Aprendizaje (CHAEA) & & & \\
Honey and Mumford Learning & Honey \& Mumford & [Honey and Mumford 1982b] & YES \\
Styles Questionnaire & VAK & [Chislett 2005] & YES \\
VAK Learning Styles Questionnaire & VARK & [VARK Learn Ltd. ] & YES \\
The VARK Questionnaire & MBTI & [Briggs and Myers 1944] & YES \\
Myers-Briggs Type Indicator (MBTI test) & Grasha-Riechmann & [Lewis 2014] & YES \\
Learning Style survey & & & \\
\hline
\end{tabular}

Tab. 3. LMS usage

The Unified Learning Style Model (ULSM) papers did not propose a method that uses a questionnaire, instead, on all related works that we manage to find on the ULSM, the only approach found was the ULSM student's learning style modeling process

\footnotetext{
${ }^{2}$ Available in the official Myers-Briggs foundation website; The official test done through the foundation is not free. Accessed on 2019/05/24 - https: / / www.mbtionline.com/TaketheMBTI
} 
VIII Congresso Brasileiro de Informática na Educação (CBIE 2019)

Anais do XXX Simpósio Brasileiro de Informática na Educação (SBIE 2019)

[Popescu 2009], created by the author and based on student's behavior during their usage of an online learning tool (like LMSs).

On the area of application of LS however, a myriad of more diverse approaches, in comparison with the identification part, were found. As mentioned early, 8 articles worked with a form of LS/Moodle integration, such as [Ferreira et al. 2018], that makes use of FSLSM, ILS and machine-learning to create a more suited environment for students. Also, in another 12 works (bringing the total to 20), we were able to identify explicit creation or usage of other LMSs (the many other works either did not specify their LMS, or used a very specific system not designed for a complete learning management or did not use one):

\begin{tabular}{|c|c|c|c|}
\hline LMS & $\begin{array}{c}\text { Total } \\
\text { amount }\end{array}$ & $\begin{array}{l}\% \text { on all the } \\
20 \text { Papers }\end{array}$ & $\begin{array}{l}\% \text { on all the } \\
102 \text { Papers }\end{array}$ \\
\hline Moodle & 8 & 40 & 7.784 \\
\hline ALS_CORR |e-LORS & $2 \mathrm{x}($ per LMS $)$ & 10x(per LMS $)$ & $1.960 x($ per LMS $)$ \\
\hline $\begin{array}{l}\text { PCMAT | ULEARN |ADOPTA } \\
\text { PeCoS-CBR |UZWEBMAT } \\
\text { SCROLL |PEDAL-NG |SeLA }\end{array}$ & $1 x($ per LMS $)$ & $5 x($ per LMS $)$ & $0.980 x($ per LMS $)$ \\
\hline
\end{tabular}

Tab. 4. LMS usage amounts

Out of the 102, 74 attempted to propose different methods of LO/LS suitability classification and recommendation through many different approaches, such as dynamic programming [Muhammad 2015], fuzzy logic classification [Anitha and Deisy 2015], data mining [Shuib et al. 2014], the ones cited on the second paragraph of the section $\mathbf{4 . 2}$ among others. As expected the list is much bigger than the examples mentioned.

Lastly, in the case of LO manipulation, we detected a total of 8 different LO models: IEEE-LOM with 19 uses, LOM with 10 uses, Bloom's Taxonomy with 6 uses, SCORM with 3 uses, LARM with 1 use, Dublin Core Metadata Initiative with 1 use, ALOCoM with 1 use, LOM - fr with 1 use and the Project CALIBRATE with 1 use.

\section{Concluding remarks}

This review was made with the intention of seeking information regarding the current scenario of the LS and LO research fields and to help new users of such on the current trends and on possible starting points. In it, we analyzed several works that touched on many LS and LO models and on even more methods of classification and recommendation of the same. A clear trend towards the use of LS and LO to personalize the learning experience on computerized learning platforms was detected, with the absolute majority of the works making use of static classification of LS methods, with a predominance of questionnaires as the main and usually only tool of classification. A small amount of works exploring dynamic methods of LS classification was found, pointing to possible areas of future research on the field. It is important to notice that the field of LO recommendation is more diverse, with many different approaches being used.

In terms of LS usage, a complete predominance of the FSLSM, both in new and old works was found, with the next most used LS being substantially less used. On the LO 
VIII Congresso Brasileiro de Informática na Educação (CBIE 2019)

Anais do XXX Simpósio Brasileiro de Informática na Educação (SBIE 2019)

classification side, a big focus on the IEEE-LOM and LOM metadata model was found, with a notable, but smaller, usage of Bloom's LO taxonomy and SCORM models.

In terms of LMS usage, Moodle was found to be the most used general propose LMS, with the other ones being used on either a smaller scale or for specific purposes.

It is interesting to point out that as LS are a point of contestation in the fields of education research [Phillips 2019], with several works pointing out the lack of solid evidence towards their efficacy[Kirschner 2017] and an overall lack of unification/consensus on what model and/or styles are truly useful (and if any is at all)[Coffield et al. 2004]. With that in mind, it is important to note that those who seek to use LS in their work must considerate these facts and properly measure their expectations.

As is shown in the literature, LS are not the ultimate answer to the creation of better learning environments and tools (and many consider them ill-suited for the formulation of an entire course), but they do attempt, with good success rates, to detect what kind of materials a student is more comfortable with, and their usage towards the betterment of the virtual LMS extra studying material recommendation process, which was the goal of the absolute majority of the the 102 selected works we evaluated, seems to better align to what their confirmed efficacy indicates.

Another note still regarding the validity of LS that we would like to add is that none of the read works attempted to validate the LS model itself. That might help us to see that, for those who work with computerized detection and recommendation, LS are, ultimately, a tool that promises to help them on their ultimate goal: to recommend and detect more suitable LO for students. It seems that most works that propose a LS model either do not properly touch on the subject of external critique(such as the Dunn and Dunn model, as pointed by [Coffield et al. 2004]), or do not state how far one can go on the use of the model in their classroom. These facts are somewhat alarming, but since our mapping did not focus on these facts, we cannot take any solid conclusion aside from speculation and second hand guessing based on other works. What we can do, given our observations, is to point out that those who seek to work with LS should perform a more thoroughly literature research before starting their works and seek to align it with what LS are known to do properly, as we commented on the paragraph above this one.

Regarding our goal of giving information to help newcomers on the use and research regarding LS models, we believe that we have reached the necessary compilation of useful information to fulfill it by showing the currently most used LS models, their official classification questionnaires, the current trends of research and the overall critics towards LS in general.

Lastly we would like to say that the field of LS recommendation still has many areas to grow, with a small amount of works focusing on automatic methods of LO recommendation and LS detection and LS model validation. Also, direct integration with popular LMS still is a lower priority on most papers, with a majority preferring to create their own systems with limited scope. An approach towards more universally used tools seems like a better way to disseminate one's work on the practical field, as we cannot expect that those several new systems will all be adopted. We hope that our work, together with the many other ones cited and revised by us, can be a helpful a stepping stone for the future advancement of this field, that, as pointed by it's critics, is a truly needed thing. 
VIII Congresso Brasileiro de Informática na Educação (CBIE 2019)

Anais do XXX Simpósio Brasileiro de Informática na Educação (SBIE 2019)

\section{References}

Alonso, C. and Gallego, D. (2000). Cuestionario honey-alonso de estilos de aprendizaje chaea. URL: www. aprender. org. ar/aulas/avadim/recursos/chaeal. rtf [01.12. 2008].

Anitha, D. and Deisy, C. (2015). Proposing a novel approach for classification and sequencing of learning objects in e-learning systems based on learning style. Journal of Intelligent \& Fuzzy Systems, 29(2):539-552.

Barbe, W. B., Swassing, R. H., and Milone, M. N. (1979). Teaching through modality strengths: concepts practices. Zaner-Bloser, Columbus, Ohio. ISBN 0883091003. OCLC 5990906.

Briggs, K. C. and Myers, I. B. (1944). Briggs Myers Type Indicator Handbook. Privately Published.

Chislett, V. (2005). Vak learning style questionnaire. https://www.businessballs.com/freepdfmaterials/vak_learning_styles_questionnaire.pdf - Access in 2019/25/05.

Coffield, F., Moseley, D., Hall, E., Ecclestone, K., et al. (2004). Learning styles and pedagogy in post-16 learning: A systematic and critical review. Learning and Skills Research Centre London.

do Nascimento, P., Barreto, R., Primo, T., Gusmão, T., and Oliveira, E. (2017). Recomendaçao de objetos de aprendizagem baseada em modelos de estilos de aprendizagem: Uma revisao sistemática da literatura. In Brazilian Symposium on Computers in Education (Simpósio Brasileiro de Informática na Educação), volume 28, page 213.

Egaña, M. L. D., Revuelta, M. J. C., and González, P. G. (2018). Analysis of the learning styles measurement tools1 análisis de las herramientas de medición de los estilos de aprendizaje. Quarterly Journal Starting year: 1952, 381:89-125.

Felder, R. M., Silverman, L. K., et al. (1988). Learning and teaching styles in engineering education. Engineering education, 78(7):674-681.

Felder, R. M. and Soloman, B. A. (1997). Index of learning styles questionnaire. Retrieved July, 20:2009.

Ferreira, L. D., Spadon, G., Carvalho, A. C., and Rodrigues, J. F. (2018). A comparative analysis of the automatic modeling of learning styles through machine learning techniques. In 2018 IEEE Frontiers in Education Conference (FIE), pages 1-8. IEEE.

Fleming, N. D. and Mills, C. (1992). Not another inventory, rather a catalyst for reflection. To improve the academy, 11(1):137-155.

Hamada, M. and Hassan, M. (2017). An enhanced learning style index: Implementation and integration into an intelligent and adaptive e-learning system. Eurasia Journal of Mathematics, Science and Technology Education, 13(8):4449-4470.

Honey, P. and Mumford, A. (1982a). The Manual of Learning Styles. Peter Honey, Ardingley House, 10 Liden Avenue, Maidenhead, Berkshire UK. ISBN: 0950844403.

Honey, P. and Mumford, A. (1982b). Manual of learning styles london: P. Schmeck, RR.

Kirschner, P. A. (2017). Stop propagating the learning styles myth. Computers \& Education, 106:166-171. 
VIII Congresso Brasileiro de Informática na Educação (CBIE 2019)

Anais do XXX Simpósio Brasileiro de Informática na Educação (SBIE 2019)

Kitchenham, B. and Charters, S. (2007). Guidelines for performing systematic literature reviews in software engineering.

Kolb, D. A. (1984). Experience as the source of learning and development. Upper Sadle River: Prentice Hall.

Lewis, M. (2014). Learning styles, motivations, and resource needs of students enrolled in a massive open online class. North Carolina, Chapel Hill. Recovered from https://cdr. lib. unc. edu/indexablecontent/uuid: 6caa790d-8235-4dd6-bd24-54ddf9bbf33e - Access in 2019/26/05.

Londoño, L. F., Duque-Méndez, N. D., and Tabares-Morales, V. (2018). Multi-agents for simulate preferences of students in lo selection. In International Conference on Practical Applications of Agents and Multi-Agent Systems, pages 360-370. Springer.

Muhammad, H. S. (2015). Using q-learning for recommend learning object on e-learning system. Proceeding of the Electrical Engineering Computer Science and Informatics, 2(1):240-242.

Nichols, M. (2003). A theory for elearning. Educational technology \& society, 6(2):1-10.

Petersen, K., Feldt, R., Mujtaba, S., and Mattsson, M. (2008). Systematic mapping studies in software engineering. In Ease, volume 8, pages 68-77.

Phillips, J. (2019). Are "learning styles" real? Dialog on Language Instruction, 29(1):3235. From the Defense Language Institute: Foreign Language Center, Presidio Monterey.

Popescu, E. (2009). Diagnosing students' learning style in an educational hypermedia system. In Cognitive and emotional processes in Web-based education: Integrating human factors and personalization, pages 187-208. IGI Global.

Popescu, E. (2010). A unified learning style model for technology-enhanced learning: What, why and how? International Journal of Distance Education Technologies (IJDET), 8(3):65-81.

Riechmann, S. W. and Grasha, A. F. (1974). A rational approach to developing and assessing the construct validity of a student learning style scales instrument. The Journal of Psychology, 87(2):213-223.

Shuib, N. L. M., Chiroma, H., Abdullah, R., Ismail, M. H., Shuib, A. S. M., and Pahme, N. F. M. (2014). Data mining approach: Relevance vector machine for the classification of learning style based on learning objects. In 2014 UKSim-AMSS 16th International Conference on Computer Modelling and Simulation, pages 170-175. IEEE.

Turkle, S. (2004). How computers change the way we think. In The Chronicle of Higher Education, volume 50, chapter The Chronicle Review, page B26. The Chronicle of Higher Education Inc. Avaible at: http://web.mit.edu/sturkle/www/pdfsforstwebpage/Turkle_how_computers_change_way _we_think.pdf - Access 2019/05/22.

VARK Learn Ltd. The vark questionnaire. http://vark-learn.com/the-vark-questionnaire/ Access in 2019/25/05. 